\title{
ADVERSE EVENTS POST FIRST COVID-19 VACCINATION IN PATIENTS WITH AUTOIMMUNE DISEASES AND HEALTHY CONTROLS: FIRST DATA FROM SAFER STUDY
}

Ketty Lysie Libardi Lira Machado1, , Edgard Torres dos Reis Neto², Gabriel Smith Sobral Vieira ${ }^{1}$, Anna Carolina Simões Moulin", Arthur Prando de Barros ${ }^{1}$, Bárbara Oliveira Souza ${ }^{1}$, Filipe Faé ${ }^{1}$, Heitor Filipe Surlo ${ }^{1}$, Isac Ribeiro Moulaz ${ }^{1}$, Laís Pizzol Pasti ${ }^{1}$, Laura Gonçalves Rodrigues Aguiar ${ }^{1}$, Luiza Lorenzoni Grillo', Marina Deorce de Lima ${ }^{1}$, Raiza Casian Tuão ${ }^{1}$, Bárbara Ferraço Dalmaso ${ }^{1}$, Rebeca Silva Moreira da Fraga ${ }^{1}$, Danielle Cristina Filgueira Alves Batista ${ }^{1}$, Thaisa de Moraes Ribeiro Espirito Santo ${ }^{1}$, Ana Paula Burian ${ }^{3}$, Andréa Teixeira-Carvalho ${ }^{4}$, Olindo Assis Martins-Filho ${ }^{4}$, Vitor Alves $\mathrm{Cruz}^{2}$, Odirlei Andre Monticielo², Adriana Maria Kakehasi ${ }^{2}$, Ciro Martins Gomes², Valderilio Feijó Azevedo², Ana Karla Guedes de Melo², Rodrigo Poubel Vieira De Rezende², Viviane Angelina de Souza², Sandra Lucia Euzebio Ribeiro², Rejane Maria Rodrigues de Abreu Vieira², Gilda Aparecida Ferreira², Marcelo de Medeiros Pinheiro², Emilia Inoue Sato², Ricardo Machado Xavier ${ }^{2}$, Gecilmara Cristina Salviato Pileggi², ${ }^{2}$, Valeria Valim ${ }^{1 \bullet \bullet}$

1.Universidade Federal do Espírito Santo, Vitória (ES), Brazil; 2.Core Group Vaccine COVID-19 Study of the Brazilian Society of Rheumatology, São Paulo (SP), Brazil; 3.Secretaria de Saúde do Estado do Espírito Santo, Vitória (ES), Brazil; 4.Fundação Oswaldo Cruz, Belo Horizonte (MG), Brazil.

*Corresponding author: kettylysie@yahoo.com.br

-These authors share the senior authorship

\section{BACKGROUND}

In the setting of the pandemic scenario caused by COVID-19, several studies were published in search of an effective vaccine. However, there are few studies in the literature that assess the safety of the COVID-19 vaccine in patients with autoimmune diseases (AID). In this context, the present study aims to evaluate the safety during 28 days after the first dose of the vaccine against COVID-19 in patients with AID.

\section{METHODS}

These data are from Safety and Efficacy on Covid-19 Vaccine in Rheumatic Disease (SAFER) study, a Brazilian multicentric prospective phase IV study to evaluate COVID-19 vaccine in AID, in the real life, in Brazil. Adverse events (AE) from a single center were assessed, after the first COVID-19 vaccination (Oxford/AstraZeneca) in patients with AID and healthy controls (HC). Inclusion criteria were $\geq 18$ years and fulfilling criteria according international classification for AID. Exclusion criteria were pregnancy, previous severe AE to any vaccine, other immunosuppression causes. Stratification of postvaccination AE was performed using a diary, filled out daily and returned at the end of 28 days.

\section{RESULTS}

A total of 377 volunteers with AID and $50 \mathrm{HC}$ were included. Groups were similar for age (43.5 vs. 41.7, $p=0.308$ ) and sex, with female predominance $(73.5 \%$ vs. $74.0 \%, p=0.937)$. Patients with spondyloarthritis $(n=64)$, systemic lupus erythematosus $(n=$ 63), rheumatoid arthritis ( $n=61)$, primary Sjögren's syndrome $(n=61)$, vasculitis $(n=31)$, systemic sclerosis $(n=14)$, inflammatory myopathy $(n=9)$, Crohn's disease $(n=49)$, ulcerative colitis $(n=11)$ and other systemics AID $(n=12)$ were evaluated. Both HC and AID showed high prevalence ( $92 \%$ vs. $89.9 \%, p=0.647$ ) but only mild $A E$. Pain at the injection $(85.7 \%$ vs. $78.4 \%, p=0.239$ ), headache ( $67.3 \%$ vs. $53.8 \%, p=0.074)$ and fatigue $(59.2 \%$ vs. $46.2 \%, p=0.089)$ were common in both groups. Overall, reactions like arthralgia ( $52.6 \%$ vs. $22.4 \%, p<0.001$ ), hematoma ( $14.1 \%$ vs. $4.1 \%, p=0.05)$, cutaneous rash ( $9.5 \%$ vs. $0 \%, p=0.024$ ) were more frequent in AID. Most participants related that they felt safer after receiving a COVID-19 vaccination, and $52.4 \%$ did not worse patient global assessment (PGA) index.

\section{CONCLUSION}

Our data indicated that Oxford/AstraZeneca vaccine is safe for patients with AID. High prevalence of mild AE was found and similar in both groups. Arthralgia, hematoma and cutaneous rash were more frequent in AID. Next analysis from SAFER and other phase IV studies are necessary to confirm these findings.

\section{KEYWORDS}

COVID-19, Vaccine, Autoimmune disease, adverse events.

Realização: 